\title{
The Role of Language in Human Information Interaction: A Social Semiotic View
}

\author{
Enyun $\mathrm{Li}^{1}$ and Yinshan Tang ${ }^{2}$ \\ ${ }^{1}$ Information Research Centre, Business Informatics Systems and Accounting, Henley Busi- \\ ness School, University of Reading, Reading \\ RG6 6UD, UK \\ e.li@pgr.reading.ac.uk, y.tang@henley.ac.uk
}

\begin{abstract}
Human information interaction is a dynamic and complex process and is affected by various factors including social and cognitive factors. This study provides a new approach to study human information interaction from a social semiotic perspective and views human information interaction as a social semiotic process. Language, as a most important information carrier, is viewed as a social semiotic system and plays a key role in human information interaction. It not only carries and stores information, but also construes information. This study analyzes the role of language in human information interaction by exploring human judgment in native language and foreign language, which implies that language affects human judgement and thinking that conducts human information activities. The effect depends on the natural logic which limits the meaning-making process of language. Language, to an extent, affects the meaning creation at information interface through which human interact with information content and process information.
\end{abstract}

Keywords: Human Information Interaction, Social Semiotics, Language, $\mathrm{Hu}$ man Judgement.

\section{Introduction}

With the development of information digitalization, various aspects of information interaction are dramatically affected and changed, which greatly affects the design and management of information systems. Human information interaction (HII), as a part of information interaction, refers to the relationship between human actors and information content. HII is increasingly attracting scholars' interest to study all aspects of the way and process that people interact with information, aiming to create better information systems.

Most studies of HII focus on human information behavior and mainly do the analysis from psychological, cognitive and social perspectives or multiapproach views. It is still at the forming stage and needs deep study of all aspects of HII in that HII is a complex and dynamic process that integrate various elements and factors to produce information and carry out information activities. Dzandu \& Tang propose a framework of HII from a semiotic perspective and divide HII into three levels - syntactic interaction, semantic 
interaction and pragmatic interaction, viewing semantic interaction as the center of HII which happens at an interface between human actors and information content known as human information interface [8]. Dzandu also holds a viewpoint that people might have different initial trust judgement in native language and foreign language [9]. This implies that languages might affect human information activities and might affect HII through which information activities are carried out, which requires further empirical explorations. This paper attempts to analyze the role of language in HII by further studying human judgement in native language and foreign language. The study is from a social semiotic perspective which analyzes all meanings in social dimensions and views language as a social semiotic system [6], which will provide a new approach to HII.

\section{Studies and Development of Human Information Interaction}

HII is an emerging area and refers to the interaction between human actors and information content. With the development of modern technology and information digitalization, researchers are increasingly addressing HII and study all aspects of the way how people produce and perceive information and carry out information activities, aiming to create better information systems. HII is a complicated process involving various aspects of human communication and attracts researchers to explore all the complexity and study the affecting factors from many areas such as philosophy, psychology, sociology, linguistics and information theory. Studies addressing HII are flourishing and fruitful in many fields, e.g. human computer interaction (HCI), computer-supported cooperative work (CSCW), human factors and library and information science (LIS) [11]. HCI focuses on the study of human computer interface to develop models and theories of interaction aiming to improve HII. CSCW addresses HII when it studies information activities such as information sharing and collaborative information retrieval in the context of collaborative and cooperative work. Human factors studies address HII when they are concerned of aspects of tools used that will affect humans to get information. In LIS, one of its subject - human information behavior (HIB) pays more attention to HII, which centers on the study of human behavior of processing information in different contexts and focuses on human interaction between people and material objects in a certain environment [11].

Approaches to these studies especially of HIB which more emphasizes on HII are mainly from perspectives of psychology, social sciences or multi-approaches. The psychological approach focuses on the cognitive factors affecting information interaction within or without context. One important theory is the information-processing model of cognition which describes that thinking is limited by the linear information structure and limited processing resources [3]. Another one is the mental models which evoke researches to study HIB by focusing on human thinking conducting information behavior, simulating presumed cognitive functions and observing various information behaviors in certain environment [3]. The psychological approach addresses cognitive processes and emphasizes individual psychological variables in HII, which helps researchers propose many useful models for information behavior such as Talor's model of prenegotiation decisions, Krikelas's model of information seeking and Dervin's sense- 
making model and Belkin's ASK model [11]. The psychological approach emphasizing cognitive stages and processes and ignores physical environment and cultural backgrounds which are important factors that affect information behavior. Therefore, some researchers devote to studying the effect of social factors on information behavior. These studies addressing social context and employ various social theories to develop information framework, such as diffusion theory, gratification theory, social network theory, social capital theory and sociolinguistic theory. They also analyze the effect of communities on information interaction like gender, age and social classes in a group [10]. Fidel proposes a framework of cognitive work analysis (CWA) of HII employing ecological approach [11]. This approach emphasizes the effect of context and addresses cognitive factors as well and analyzes human actors' information interaction with its environment. The framework is effective in analyzing information behavior within a particular community, especially the analysis of collaborative information retrieval (CIR).

Until now, the studies addressing HII focus on the process and relevant factors affecting HIB, which greatly contributes to the development of information retrieval, human-computer interaction and digital libraries. HII is a complex and dynamic process, and the study of it is still at the forming stage and needs to explore all its complexity.

\section{$3 \quad$ Language and HII}

\subsection{A Social Semiotic View of HII}

First, it is necessary to discuss the definition of information. Scholars from different arears give different definitions with different emphasis of information. Shannon \& Weaver define that information is the reduction of uncertainty addressing the function or purpose of information in information transmission [2]. Davis and Ohlson define information as processed data "that is meaningful to the recipient and is of real or perceived value in current or prospective actions or decisions" [4]. Fidel gives a similar definition viewing information as a thing that has meaning and is useful for decision making [11]. Dzandu \& Tang's study on HII emphasizes that human actors interact with information by making meanings within a certain environment from a semiotic view [8]. Thus, meaning is the main concern of information and information is construed on the base of meaning processed with content within a certain environment.

HII is in nature human actors' meaning-making process with information content. The central meaning-making process takes place at a semantic interface known as human information interface through which information and meaning are transformed. All the interaction takes place within a certain social environment and is affected by various factors including social and cultural backgrounds, situational background and personal backgrounds. The information content is represented by information carriers such as words, images, sounds, colors, etc. All the information carriers are of social meaning potential from social semiotic perspective, which are called as social semiotic resources/systems. HII is human's interaction with social semiotic resources and making meanings within a certain environment. Thus, HII is in nature a social semiotic 
process between human actors and social semiotic resources/information content. The central concern of human information interface through which information is produced and information activities are carried out is the meaning creation (Fig. 1).

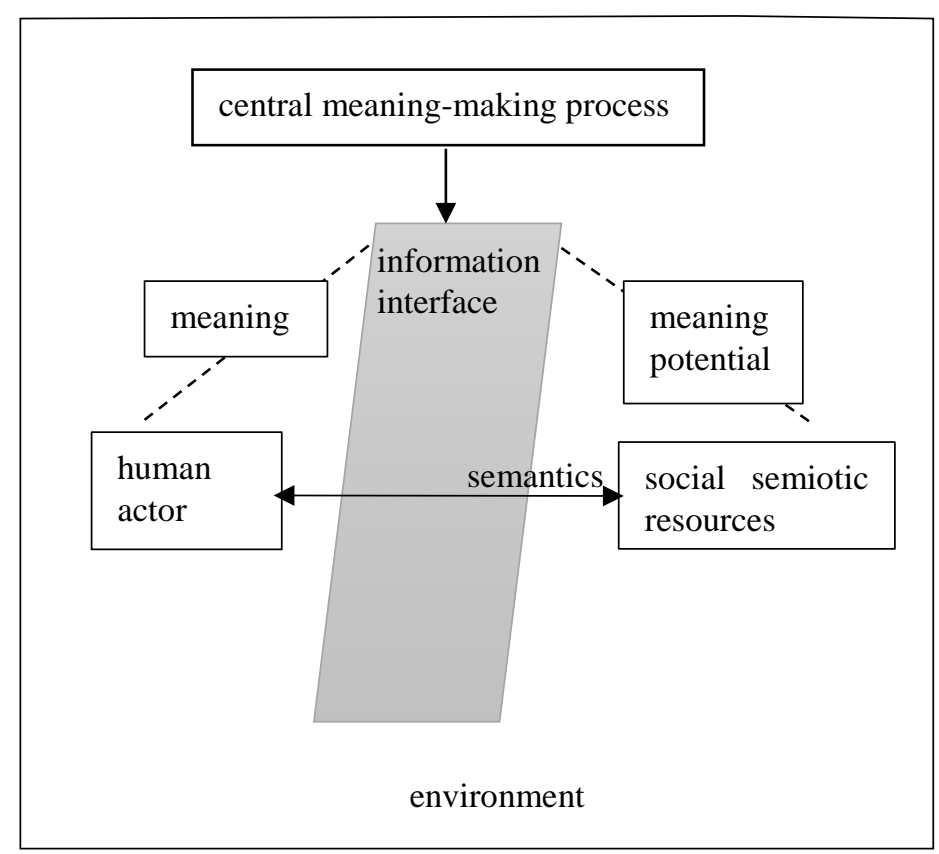

Fig. 1. A social semiotic view of HII

\subsection{A Trial of People's Judgment in Native Language and Foreign Language}

Various factors affect the meaning creation at human information interface, e.g., social environment, situational context, individual's differences. Language is a most significant information carrier although not the only one and important in storing and transmitting information. Language is viewed as a social semiotic resource and plays a key role in constituting social structures [5]. It is not only an information carrier but also an element of social and cultural environment. Thus, it is very significant in HII and communication. Dzandu describes that people might have different initial trust judgement in native language and foreign language [9]. Keysar and his team also carry out series of experiments on risk judgements among people whose native language was English and foreign language was Japanese. The experiments imply that people tend to make less risky judgment in foreign language. They attribute the results to people's different reasoning systems in different languages from psychological perspective. Dr Keysar wrote: "A foreign language provides a distancing mechanism that moves people from the immediate intuitive system to a more deliberate mode of thinking" [1]. These experiments show that human judgement might be affected by different languages. The 
experiments are still limited in supporting the results. There are too many factors affecting people's judgment and more empirical explorations are required.

To further test whether people have different judgements in different languages, a trial was designed with enlarged types of judgements, questions and languages. A questionnaire was used in the trial and languages are Chinese (native language) and English (foreign language). The questionnaire contained five questions about people's judgement in a certain situation including initial trust judgment, moral judgement. The original materials were in Chinese and the English version was equivalent translation. Each question was followed by likelihood scales ranging from 1 to 5 ( $1=$ very highly likely to do, $5=$ not very likely to do).

In the trial, 60 people (19 males, 41 females) participated in the experiment. Their age ranged from 20 to $40(<20 \mathrm{rs}=6,20 \mathrm{ys}-30 \mathrm{ys}=49,30 \mathrm{rs}-39 \mathrm{rs}=5)$. All participants' native language should be Chinese, and foreign language should be English. Among the participants, 30 people took part in Chinese questionnaire while the other 30 people participated in English equivalent questionnaire. Two participants were excluded from the analysis, either because the participant's foreign language was not English or the participant did not do the questionnaire at all. 52 participants were Chinese university students living in China and the other 8 participants were Chinese people living or working in UK. The participants' level of English proficiency was not tested. Questionnaires were sent to participants randomly. Participants were asked to give their judgement on the events by giving a likelihood scale and a brief explanation.

\section{$4 \quad$ Results and Discussion}

In the trial, the collected data was divided into two groups according to languages and was analyzed by descriptive analysis and non-parameter analysis with SPSS. According to the significance test ( $p$ value) between the two language groups which was analyzed by non-parameter analysis, except question $5(\mathrm{p}=0.10)$, the results showed that the $\mathrm{p}$ value of other questions was less than 0.05 , which demonstrated that people's judgement in native language and foreign language were significantly different.

Although the $\mathrm{p}$ value of question 5 was 0.10 , the mean values of likelihood ratings ( $M$ value) between Chinese group and English group were different $\left(M=3^{\prime} 45\right.$ and $\mathrm{M}=3.9$ respectively). The mean likelihood ratings of questions between each group were illustrated in Figure 2, which showed people made different judgment on the events between the two language groups. The mean values of foreign language groups (English) were higher than that of native language groups (Chinese). Question 1,2 and 5 were about initial trust judgement. Question 3 and question 4 were about moral judgement. According to the mean values of each language group, people might tend to make more negative decisions on initial trust and moral events in a foreign language.

In the trial, the question about initial trust (question 2) is more significantly different than other questions in the language groups $(\mathrm{p}=0.00)$, which implies that people's initial trust judgment might be more easily affected by native language and foreign language. This is consistent with the result of Dzandu's experiment. However, the results still 
need further experiments to test it because either the present trial or Dzandu's experiment is still limited in supporting the results. The samples are too small and the participants' backgrounds are too complicated. More variables need to be further controlled, e.g., age ranges, job backgrounds and foreign language proficiency, which would affect human judgement.

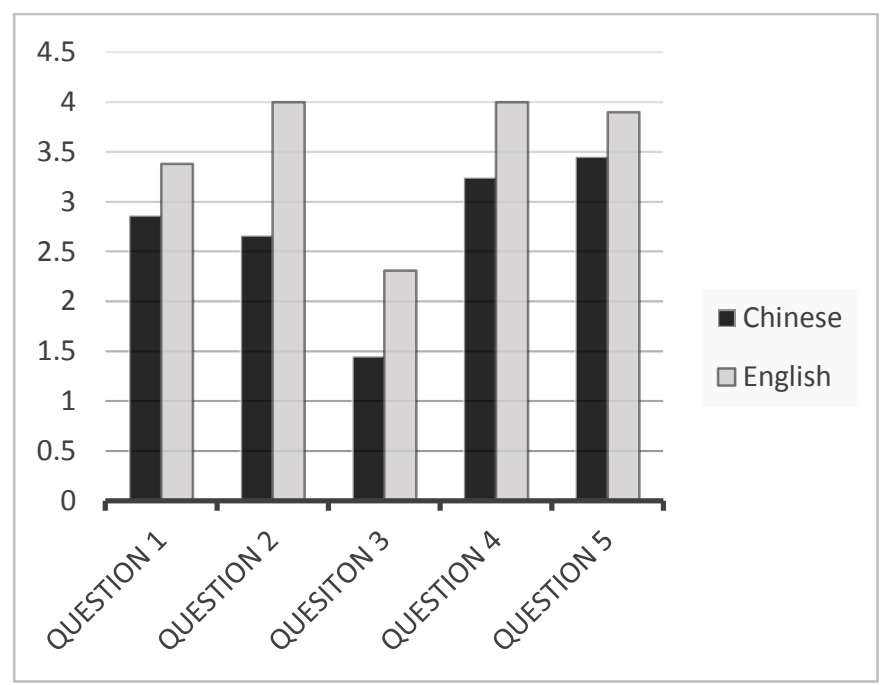

Fig. 2. Mean likelihood ratings for the groups of items by language. Native language: Chinese; Foreign language: English.

The result is consistent with Halliday's viewpoint that people have different emphasis on meanings when perceiving the same events in different languages. Language, as a social semiotic system, embodies the relations between language, meaning and functions within society, just as what Halliday describes "language is as it is because of the functions it has evolved to serve in people's lives" [5]. The functions of language are realized by the semantic system of language, which is stratified into strata consisting of phonology/morphology, lexicogrammar and semantics. The central meaning-making resource of language takes place in its lexicogrammar and semantics which are called as content plane of language. The semantic layer is the interface where experience and information are "transformed into meaning" and the lexicogrammar layer conducts "the way this transformation takes place" [6]. Different languages are different social semiotic systems and differ in their meanings, not only differing in basic units such as words, sounds and meanings but also differing in the way they are combined to make meanings. This determines the meaning-making resources and affects "what the members of the community attend to" perceive the world around them [5]. Even people who can speak two languages have "the same perception of events", but "they pay attention to different characteristics of them and so build up a rather different framework for the systematization of experience" [5]. For example, in the trial of question 3, the participants had the same perception that the situation was a kind of dilemma, either in Chinese or in English. However, participants' responses to the situation in native language 
and foreign language were different. Native language and foreign language as two different social semiotic systems constituting their own social meanings have different meaning-making resources and would affect people's judgement of the world.

The study also extends Whorf hypothesis that language affects its native speaker's thinking [12]. The result of the trial implicates that human thinking is not only affected by native language but also affected by foreign language. Languages affect human thinking and the meaning-making process. Thinking is the way human mind works which conducts all human activities. In most situation, human think with language. In the process that human learn or acquire a language, the system of each language forms a meaning framework which could affect human thinking. HII refers to the relationship between human actors and information content and is in nature human's meaning-making process with information carriers. The meaning-making process takes place at an information interface through which meaning is created and information is processed, which is conducted by human thinking.

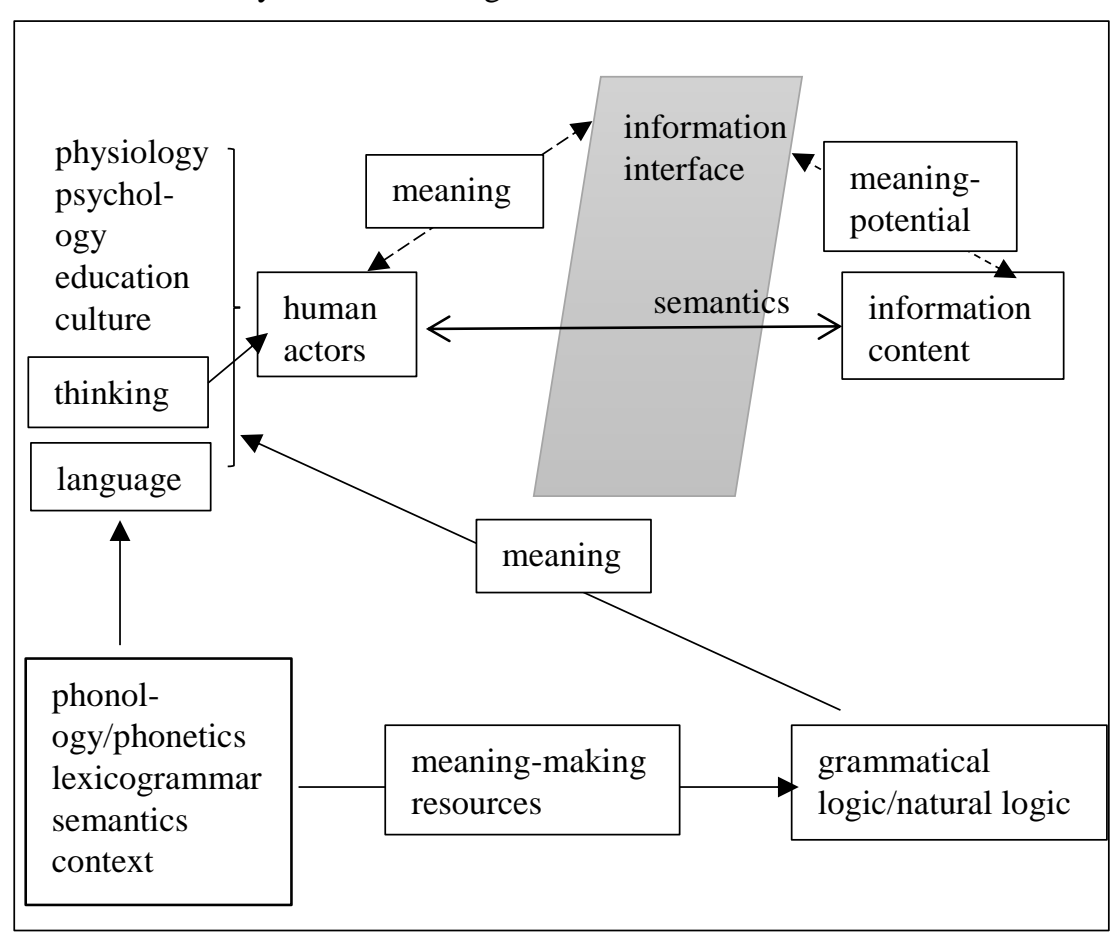

Fig. 3. Language in human information interaction

In HII, human actors' backgrounds including physiology, psychology, education, culture, cognition and language are important factors affecting human actors on making 
meanings and performing information activities (Fig. 3). Among these factors, language is a most significant one. It not only carries and transmit information, but also construes information by affecting human information interface and thus affects human information activities, as what showed in the trial that native language and foreign language affect human judgement and decision making in the same situation. Language, as a social semiotic system, affects human thinking on the basis of its semantic system which is stratified into phonology/phonetics (expression), lexicogrammar (wording), semantics (meaning) and context [6]. The strata of language work together to realize meaning logically, which is mainly realized on the meaning base - the three dimensions of meaning: ideational, interpersonal and textual meaning and each is realized by its grammatical system within a context. Halliday describes "Language is powered by grammatical energy" [7]. The "grammatical energy" to generate meaning mainly exist in lexicogrammar and semantics between which the realizational relationship is natural. The realization of meaning is based on the natural relationship or natural logic, which affects human thinking and meaning and creation. Thus, the effect of language on human thinking lies in the natural logic. The logic of language in nature exists in the various systems of language which influence human in choosing language items to realize meaning. The natural logic is the framework or scaffolding of meaning.

The study explores human judgment in native language and foreign language and analyzes the role of language in HII, emphasizing the central meaning-resources of language and their realization of meaning. It is meaningful for the study and development of information systems of which user, system, content are three important elements. At each level including user-system management, system-content management and usercontent management, various factors affect user's information activities, among which human factors are a most important and complicated one. The study of the role of language in HII is a deep study of human elements affecting information activities through information systems. This will be helpful for the design and management of information systems, especially for communities of multilingual backgrounds which would influence human information activities. Analyzing and digitalizing the differences in languages and their effect on information activities will be greatly important for information systems management and services to reduce language barriers. For example, the appraisal systems of different languages have similar items, however, may have different positive effect and negative effect on human thinking and judgement.

This will also promote the study of natural language understanding which is a most difficult topic in artificial intelligence (AI). The study implies that human judgement and thinking is different in native language and foreign language, which is resulted from their different social semiotic systems which is of natural logic. To help a machine understand and produce natural language is to help a machine have natural language logic based on the semantic system of language in that natural logic of language lies in the systems of language. Digitalizing and analyzing the central meaning-making resources or semantic systems of different languages and the way of combination to make meanings which would affect human thinking will be a way to help machines think grammatically and act grammatically. This is also meaningful for foreign language teaching and learning in which language logic is an important topic. 
The study of human judgment in native language and foreign language also extends previous related studies which are focused on human psychological process of language process. This study explores the influence of foreign language on human judgement from social semiotic perspective and emphasizes the logic of language which conducts the meaning-making re-sources of language to realize meaning that affects human judgement.

\section{Conclusion}

The study provides a new approach to HII by analyzing the role of language in HII from a social semiotic perspective. HII is a dynamic and complex process and is affected by various factors including social and cognitive factors. Previous studies addressing HII analyze these factors mainly from cognitive perspective or social and cultural perspective. The social semiotic study of HII view information as a subclass of meaning and HII as a social semiotic process in which human actors interact with information content and make meanings within a certain social environment. The central meaning-making process takes place through information interface between human actors and information content where information is transformed and interpreted based on the meaning base within a certain environment. Language is not only an important information carrier, but also plays a key role in construing information on the base of its semiotic system. The study analyzes the role of language by exploring human judgment in native language and foreign language, which implies that human judgment and thinking is affected by languages. Language construes meaning with its semantic systems conducted by natural logic, which affects human's meaning creation and affects human thinking, thus affecting human information interface through which meaning is created and information is transformed and interpreted.

\section{References}

1. B Keysar, S L. Hayakawa, \& S G An.: The Foreign-Language Effect: Thinking in a Foreign Tongue Reduces Decision Biases. Psychological Science. (2012) Psychological Science $\mathrm{XX}(\mathrm{X}) 1-8$.

2. Claude E. Shannon and Warren Weaver (1964). The Mathematical Theory of Communication. University of Illinois Press.

3. Gary Marchionini.: Human-Information interaction research and development. Library \& Information Science Research 30 (2008) 165-174.

4. M. W. Hill.: The Impact of Information on Society: An examination of its nature, value and usage. K.G.Saur Munchen (2005) p16.

5. M. A. K. Halliday.: Language as social semiotic. London: Edward Arnold. (1978). p4, p198, p199.

6. M. A. K. Halliday \& Christian M. I. M. Matthiessen.: Construing Experience Through Meaning: A Language-based Approach to Cognition. London: Continuum. (1999). P604.

7. M. A. K. Halliday.: On Grammar. In: Collected Works of MAK Halliday, Vol. 1. Edited by Jonathan Webster. Continuum. (2002). p387. 
8. M. D. Dzandu, Y. Tang.: Beneath a learning management system - Understanding the human information interaction in information systems. ScienceDirect. (2015).

9. M. D. Dzandu.: initial trust judgement in native language and foreign language. Personal Communication (2015).

10. R. Fidel, A. M. Pejtersen, B. Cleal, H. Bruce.: A Multidimensional Approach to the Study of Human Information Interaction: A Case Study of Collaborative Information Retrieval. Journal of the American Society for Information Science and Technology. (2004) 939-953.

11. R. Fidel.: Human information interaction: an ecological approach to information behavior. London: Cambridge, Massachusetts, the MIT Press. (2012).

12. Whorf. B. L.: Language, mind, and reality. In: J.B. Carroll (ed), Language, thought and reality. Cambridge, Massachusetts: the MIT Press. (1956).

\section{Appendix: the 5 questions in the questionnaire}

A: There is a person who always tries to help others but ends up making everything worse. Given that you do not know the person at all,

Question 1. What would be your first impression of this person?

Question 2. If you might work with the person, what would be your trust in the person? B:

Question 3. How likely are you going to lift up a senior who falls over?

Question 4. Given that a ship in the sea is damaged, to save the people on the ship, you would have to push a person into the sea. How likely are you going to agree the idea? Question 5. What would be your trust in a person who once was addicted to drug? 